\title{
Spinal cord infarction secondary to nucleus pulposus embolization in pregnancy
}

\author{
Shweta Uppal ${ }^{1}$, Subasini Dash ${ }^{2}$, Leroy Sharer ${ }^{1}$, William Clark Lambert ${ }^{1}$, Debra S Heller ${ }^{1}$ \\ and Patrick Pullicino ${ }^{2}$ \\ ${ }^{1}$ Department of Pathology and Laboratory Medicine and ${ }^{2}$ Department of Neurosciences, UMDNJ-New Jersey \\ Medical School, Newark, NJ, USA
}

\begin{abstract}
Nucleus pulposus (NP) embolism is an extremely rare cause of spinal cord infarction. To our knowledge, it has not been reported in pregnancy in the English literature. A 41-year-old pregnant woman presented with clinical symptoms initially attributed to a transverse myelitis. After a complicated clinical course, she expired, and was found at autopsy to have NP embolism to the spinal cord. In conclusion NP embolism is a rare cause of spinal cord infarction, and should be considered in the differential of a patient presenting with symptoms compatible with spinal cord infarction in the pregnant as well as nonpregnant state.
\end{abstract}

Modern Pathology (2004) 17, 121-124, advance online publication, 19 November 2003; doi:10.1038/modpathol.3800037

Keywords: intervertebral disk; spinal cord; infarction

Embolization of fibrocartilaginous material to the spinal cord vessels is a rare cause of spinal cord infarction. The etiology is unknown, although some cases have been reported to occur following trauma, which may be minor. To our knowledge, nucleus pulposus (NP) embolism to the spinal cord vessels has not been reported during pregnancy in the English language literature. We herein report such a case and review the salient literature on this topic.

\section{Case}

A 41-year-old G5P3105 woman presented to the labor and delivery service at $25+$ weeks gestational age with a chief complaint of sudden onset of lower extremity tingling, weakness, and inability to walk. The weakness developed in less than $30 \mathrm{~min}$. She denied trauma, viral infection, contact with ill individuals, unusual food ingestion, or the use of alternate medicines. The patient had five other children, and her prior pregnancies were uneventful.

On examination, she had decreased muscle tone, complete loss of strength, and absent deep tendon reflexes in the lower extremities. Plantar responses were absent. Sensory examination revealed the

Correspondence: D Heller, Department of Pathology-UH/E158, UMDNJ-New Jersey Medical School, 185 South Orange Avenue, PO Box 1709, Newark, NJ 07101, USA.

E-mail: hellerds@umdnj.edu

Received 13 August 2003; revised 26 September 2003; accepted 16 October 2003; published online 19 November 2003 absence of perception to fine touch, pinprick, vibration, temperature, and joint position in the lower extremities below the T10 level. Rectal sphincter tone was absent. The remainder of the neurological examination was normal.

Laboratory examination revealed normal serum chemistry and hematology. The patient's antithrombin-III level was mildly low at 74 (normal 85-120). Protein C, protein S, dilute Russell viper venom times (for lupus anticoagulant), and anticardiolipin antibody were normal. An Magnetic Resonance Imaging (MRI) of cervical, thoracic, and lumbar spine with and without contrast did not reveal any abnormalities, but showed mild disc protrusions at the C3-4 and C4-5 levels producing mild cervical stenosis and mild flattening of the thecal sac and cord. Lumbar puncture showed normal cerebrospinal fluid with one cell, protein $36 \mathrm{mg} / \mathrm{dl}$, and glucose $62 \mathrm{mg} / \mathrm{dl}$. The patient continued to be symptomatic, and an MRI of the spine was repeated a day later. Increased signal was noted within the cord from the conus to T6-7, compatible with either cord infarction or myelitis. An MRI of the brain with and without contrast was normal. Somatosensory evoked potentials to the right and left median nerve stimulations were normal. Cortical potentials were absent with right and left peroneal nerve stimulation. These findings were consistent with a disturbance of the posterior columns bilaterally.

Initially, the clinical impression was of transverse myelitis vs spinal cord infarction. The patient had findings suggestive of involvement of both posterior and anterior columns of the spinal cord, which was atypical for spinal cord infarction. The patient was 
given a trial of dexamethasone $(60 \mathrm{mg} /$ day for 5 days) followed by a tapering course of prednisone $60 \mathrm{mg}$ for 2 days without any improvement. On hospital day 10, the patient complained of mild abdominal pain. Later, despite a large bowel movement, the patient's abdomen was still moderately to severely distended and tympanitic. She became tachycardic (150 beats/min) and tachypneic with a respiratory rate of at least $40 \mathrm{~min}^{-1}$. The differential diagnosis at this point included pulmonary embolism and aortic dissection. The patient had a cardiorespiratory arrest while the CT scan was being performed, and she was successfully resuscitated. An emergent Cesarean-section was performed and a stillborn infant was delivered. Upon entry into the peritoneal cavity fecal matter was apparent. A bowel perforation of the cecum was noted, and a partial colectomy was performed. The patient was then transferred to the surgical intensive care unit, where she remained in critical condition, intubated, and requiring pressors. She was septic, and she developed acute respiratory distress syndrome (ARDS) and coagulopathy requiring transfusion of multiple blood products. A second laparotomy was performed 4 days after the first, and the distal ileum, cecum, and proximal ascending colon were resected because of perforation with focal infarction and ischemic changes. On postoperative day 8, brain flow scan showed no flow, and artificial support was discontinued.

\section{Surgical Pathology}

Histologic examination of the resected colon disclosed perforation and focal infarction, without any foreign material noted in the blood vessels, on review after the spinal cord sections from the autopsy had been examined. The placenta had subchorionic hemorrhage, but again no occlusive material was observed in the vessels. A review of the second bowel perforation specimen also failed to reveal any occluded vessels.

\section{Autopsy Findings}

The inferior vena cava contained thrombus and the iliac veins had a saddle thrombus.

On microscopic examination, there were multiple fibrin thrombi in arterioles in the lungs, with early ARDS. There was also severe acute peritonitis. Pertinent negatives included an unremarkable vertebral column, and no evidence of an atrial myxoma or other lesions in the cardiac chambers.

\section{Neuropathologic Findings}

An examination of the brain disclosed gross and microscopical changes of a nonperfused brain with autolysis (the so-called 'respirator brain'), with marked brain swelling, bilateral transtentorial uncal, and midline herniation, Duret hemorrhage in the base of the pons, and herniation of the cerebellar tonsils. The lower spinal cord, which was not autolyzed, exhibited extensive necrosis and cavitation, most marked at the L1 level but extending as high as T9, with macrophages removing necrotic tissue, on histological examination. The dorsal cord was more severely involved than the ventral at the affected levels, but some changes were also noted in the anterior gray and white matter. Many small arteries, mainly in the dorsal leptomeninges of the lower thoracic and lumbar cord, were occluded by mildly basophilic material (Figure 1) that was strongly positive on Alcian blue stain (Figure 2). Occasional vessels within the cord parenchyma and, rarely, in the ventral roots were similarly occluded. This material had the typical appearance of fibrocartilaginous tissue. The anterior spinal artery at all cord levels was patent, with no evidence of occlusion (Figure 3). With immunocytochemistry, the fibrocartilaginous material was negative when reacted with antibodies to S-100 protein, alpha-

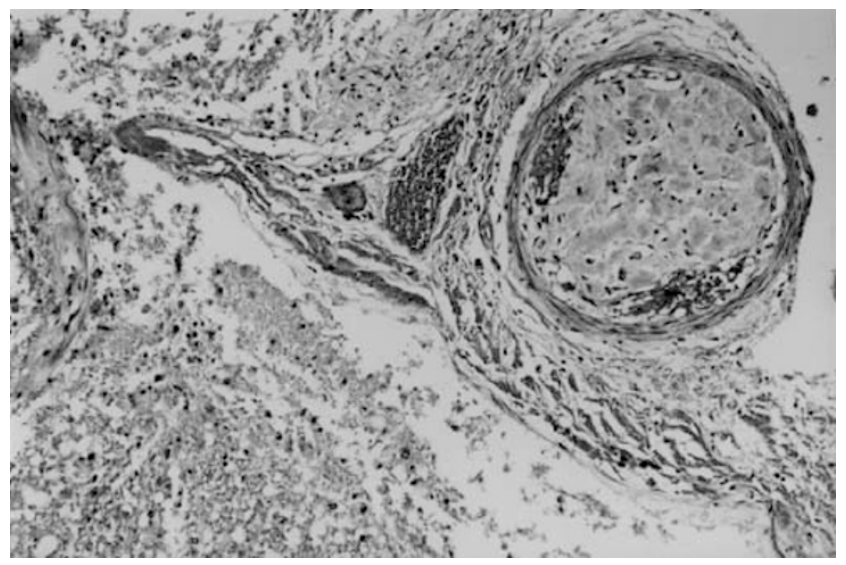

Figure 1 Vessel occluded by fibrocartilaginous material, in dorsal leptomeninges of L3 spinal cord. (Masson trichrome stain, X175.)

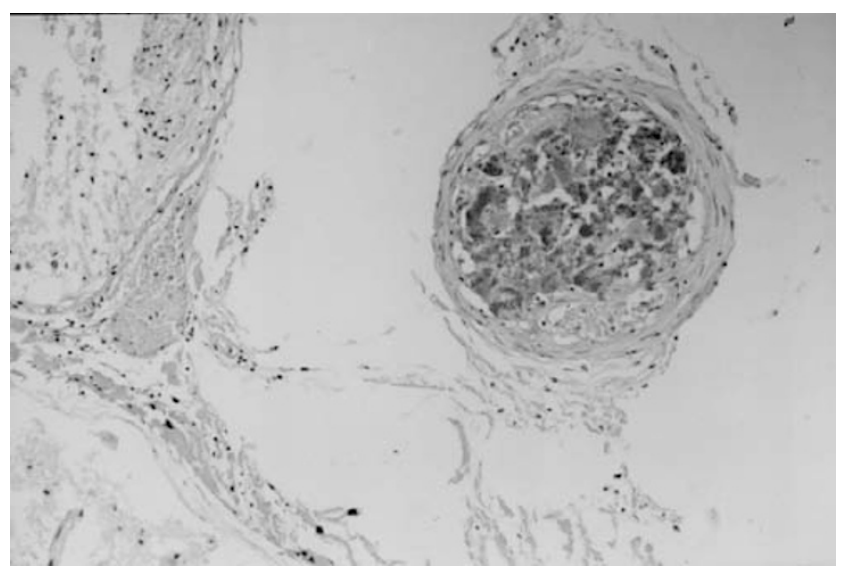

Figure 2 Vessel occluded by fibrocartilaginous, Alcian blue positive material, dorsal leptomeninges, L3 spinal cord. (Alcian blue stain, X175.) 


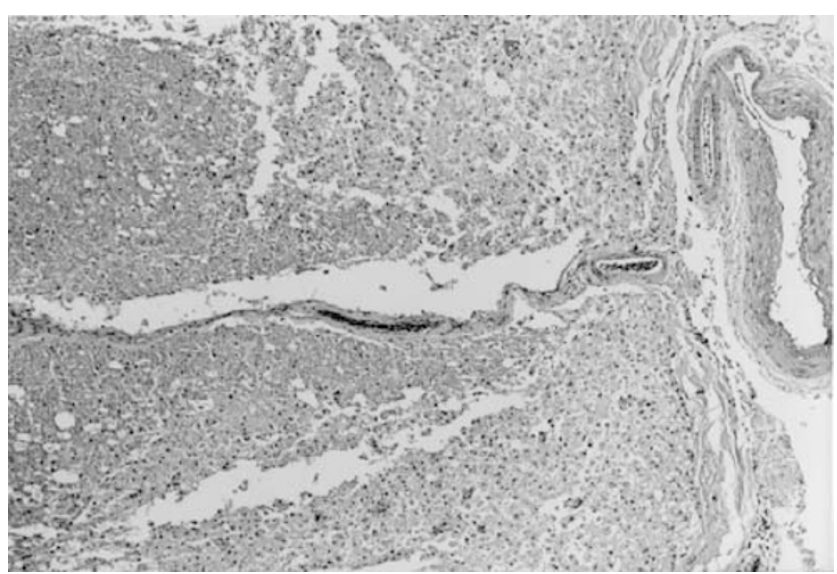

Figure 3 Patent anterior spinal artery (bottom of photomicrograph), with zones of myelomalacia on either side of the ventral sulcus of the spinal cord, T12 level. The parenchyma in the upper portion of the photograph, more medially, near the ventral canal, is intact. The anterior spinal artery was patent at all levels of the cord. (hematoxylin and eosin, X175.)

fetoprotein, and beta-human chorionic gonadotropin ( $\beta$-HCG). It stained lightly, with the use of an antibody to placental alkaline phosphatase (PLAP). This material was not seen in the blood vessels in the systemic organs in this case, and it was not present in the vessels of the brain.

\section{Discussion}

Spinal cord infarction due to embolization of fibrocartilaginous material is a rare, yet well-recognized phenomenon, occurring more often in women rather than in men. ${ }^{1}$ Only one prior case of this phenomenon occurring in a pregnant woman has been reported in the German literature, and we have found none in the English literature. ${ }^{2}$ It has been associated in some cases with trauma, which is often minor, although there was no indication of trauma in this case. Most of the cases that have been described in the literature have involved the territory of the anterior spinal artery. This case is unusual, since most of the emboli were in the dorsal spinal arteries, with more severe infarction of the dorsal half of the cord than the ventral half. However, some vessels in the ventral circulation were clearly occluded, although the anterior spinal artery itself was patent at all levels. As is usually the case, the cause of death was related to secondary events, in this case bowel distention with resultant necrosis and perforation, leading to peritonitis, sepsis, ARDS, and death. As is also typical of such cases, there was no evidence of embolization of the material to any other tissues in the body. Other possible sources of the material in the spinal cord vessels such as organizing thrombi or embolized material from an atrial myxoma could have potentially occurred; however, there was no evidence of an atrial myxoma, and the alcian blue positivity would not be expected in an organizing thrombus. Also mitigating against vertebral thrombi was that the MRI did not reveal any abnormality of the intervertebral disks or vertebrae during life, nor did the gastrointestinal tract show emboli at the surgical resection or at autopsy.

NP embolism was first reported by $\mathrm{Naiman}^{3}$ in 1961 who reported a 15-year-old boy, who after minor trauma died as a result of spinal cord infarction secondary to embolized disc material. Since then a limited number of additional cases have been reported.

The NP is a semi-fluid gelatinous fibrocartilagenous cushion, rich in mucopolysaccharides, containing a few multinucleated notochordal cells that disappear by the end of the first decade of life. ${ }^{4}$ Arterial vascularization is present early in life, and the material becomes avascular in adolescence. ${ }^{5}$

There have been less than 40 cases of this phenomenon reported so far in the literature. Tosi et $a l^{6}$ reviewed the literature and summarized 32 cases. Women were more affected than men, the reason for which is unclear. Most of these women were of child-bearing age. Most patients died, ranging from hours up to 6.6 years. Embolism to the anterior spinal artery was more common rather than to the posterior spinal artery. The clinical history preceding the onset of symptoms was variable in the reported cases, including falls, symptoms on awakening from sleep, and in some cases the onset is sudden with no identifiable antecedant. $^{2,6-12}$

How the disc material enters into the vascular system is not clear, and many theories have been proposed. The blood supply to the spinal cord is characterized by an extensive network of epidural arteriovenous anastomoses, as demonstrated by postmortem intravascular injection of gelatinated ink. ${ }^{13}$ Vuia and Alexianu ${ }^{14}$ showed that arteriovenous shunts exist between arteries and veins surrounding the posterior root ganglia and nerve roots, as well as between arteries and veins in the epidural space. Naiman ${ }^{3}$ postulated that an intervertebral disc ruptures laterally causing damage to an adjacent radicular artery with entrance of disc material into the arterial circulation. An alternate hypothesis is that high axial loading causes increased pressure within abnormally vascularized but unruptured disc, with injection of semifluid NP material into small arteries and retrograde spread to a radicular artery.

Feign et $\mathrm{al}^{7}$ suggested that in cases with predominant venous embolization, extrusion of NP into sinusoids and veins of the vertebrae via Schmorl's nodes might be the mechanism of embolization. Srigley et $a l^{15}$ suggested that retrograde venous flow from vertebral marrow sinusoids through Batson's plexus into the spinal veins could explain some cases.

Embolism of NP is not limited to the spinal cord. Toro-Gonzalez et $a{ }^{16}$ reported acute ischemic stroke from fibrocartilaginous embolism to the middle 
cerebral artery in a previously healthy 17-year old female who fell during a basketball game, followed by left hemiparesis, right uncal herniation, and death over a 3-day period. Schreck et $a l^{17}$ reported NP pulmonary embolism in a 57-year-old male secondary to spasmodic back extensions following a fatal systemic reaction to radiocontrast used in fluroscopic discography.

The occurrence of NP embolism following either absent or minor trauma, and the infrequency following major accidents and surgeries, which increase the risk of hematogenous embolization, suggests that factors other than the arteriovenous circulation of the spinal cord contribute to the condition. The etiology of the embolic phenomenon in this case is unknown. It is possibly related in some way to the woman's pregnancy, but this is merely a speculation. We could find no reports explaining the increased risk in women, nor relating this either to hormonal cycles or to pregnancy. NP embolism should be considered in patients both pregnant and nonpregnant who present with symptoms attributable to spinal cord infarction.

\section{References}

1 De Girolami U, Frosch MP, Tator CH. Diseases of the spinal cord and vertebral column. In: Graham DI, Lantos PL (eds). Greenfield's Neuropathology, Vol I. London, UK, Arnold Publishers, 2002, pp. 1065-1068.

2 Bodechtel G. ber differentialdiagnostische Schwierigkeiten auf den Grenzgebieten der inneren Medizin zur Neurologie. Münchner Med Wochenschr 1968;110: 969-980.

3 Naiman JL, Donohue WL, Prichard JS. Fatal nucleus pulposus embolism of spinal cord after trauma. Neurology (Minneap) 1961;11:83-87.

4 Warwick R, Williams PL, (eds). Grey's Anatomy, 35th British edn. WB Saunders: Philadelphia, PA, 1973, pp 412-413.
5 Bruno MS, Ober WB, Flynn JT, et al Sudden onset of severe chest pain and paralysis. NY State J Med 1969;69:446-454.

6 Tosi L, Rigoli G, Betramello A. Fibrocartilaginous embolism of the spinal cord: a clinical and pathogenetic reconsideration. J Neurol Neurosurg Psych 1996;60:55-60.

7 Feign I, Popoff N, Adachi M. Fibrocartilagenous venous emboli to the spinal cord with necrotic myelopathy. J Neuropathol Exp Neurol 1965;24:63-74.

8 Jurkovic I, Eiben E. Fatal myelomalacia caused by massive fibrocartilagenous venous emboli from nucleus pulposus. Acta Neuropathol (Berlin) 1970;15:284-287.

9 Hubert JP, Retif J, Brihaye J, et al Infarctus medullaire par emboles du hoyan pulpaux. Acta Neurol Belg 1974;74:297-303.

10 Kepes JJ, Reynard JD. Infarction of spinal cord and medulla oblongata caused by fibrocartilaginous emboli. Virchows Arch (Pathol Anat) 1973;361: 185-193.

11 Peiffer J, Wenig CH, Mausle E. Akutes Querschnitt ssyndrom durch emboli in von nucleu. Dtsch Med Wochenschr 1976;101:583-586.

12 Hubert JP, Ectors M, Ketelblant-Balasse $\mathrm{P}$, et al Fibrocartilaginous venous and arterial emboli from nucleus pulposus in the anterior spinal system. Eur Neurol 1974;11:164-171.

13 Ogata J, Feigin I. Arteriovenous communications in the human brain. J Neuropathol Exp Neurol 1972;31: 519-525.

14 Vuia O, Alexianu M. Arteriovenous shunt in the spinal cord circulation. Acta Neurol Scand 1969;45:216-223.

15 Srigley JR, Lambert CD, Bilbao JM, et al Spinal cord infarction secondary to intervertebral disc embolism. Ann Neurol 1981;9:296-301.

16 Toro-Gonzalez GT, Roman LN, Roman GC, et al Acute ischemic stroke from fibrocartilaginous embolism to the middle cerebral artery. Stroke 1993;24: 738-740.

17 Schreck R, Manion WL, Kambin P, et al . Nucleus pulposus pulmonary embolism. Spine 1995;20: 2463-2466. 